\title{
Tingkat Pengetahuan Ibu tentang Difteri Berhubungan dengan Perilaku Pencegahan Penyakit Difteri di Dusun Ngrame Kasihan Bantul
}

\author{
Muryani ${ }^{1}$, Ircham Machfoedz ${ }^{2}$, Muh. Nur Hasan ${ }^{3}$ \\ 1,2,3 Sekolah Tinggi IImu Kesehatan Alma Ata Yogyakarta \\ Jalan Ringroad Barat Daya No 1 Tamantirto, Kasihan, Bantul, Yogyakarta
}

\begin{abstract}
Abstrak
Perilaku memiliki peran hingga 30-35\% terhadap derajat kesehatan, termasuk perilaku pencegahan penyakit difteri. Hasil beberapa penelitian di DIY pernah terjadi kejadian luar biasa (KLB) difteri. Berdasarkan survey, di Dusun Ngrame pernah ada kejadian penyakit difteri dan diduga erat hubungannya dengan perilaku hidup bersih dan sehat. Tujuan penelitian untuk mengetahui hubungan tingkat pengetahuan ibu tentang difteri dengan perilaku pencegahan penyakit difteri di RT 01, 02, dan 04 Dusun Ngrame Kasihan Bantul 2011. Jenis penelitian analitik dengan pendekatan cross sectional. Sampel diambil menggunakan teknik purposive sampling dengan sampel berjumlah 69 orang ibu. Alat penelitian menggunakan dua instrumen berbentuk kuesioner pengetahuan dan perilaku. Hasil penelitian dianalisis dengan menggunakan uji statistik kendall tau. Hasil penelitian tingkat pengetahuan ibu tentang difteri di RT 01,RT 02 dan RT 04 Dusun Ngrame mayoritas baik yaitu sebanyak 59 orang (85,5\%) dan perilaku pencegahan penyakit difteri mayoritas baik yaitu 58 orang $(84,1 \%)$. Hasil uji korelasi kendall tau diperoleh $p$ value $0,000<\alpha(0,05)$ hingga dapat disimpulkan ada hubungan antara tingkat pengetahuan ibu tentang difteri dengan perilaku pencegahan penyakit difteri di RT 01, RT 02 dan RT 04 Dusun Ngrame Kasihan Bantul 2011 dengan koefisien korelasi sebesar 0,729. Kesimpulan ada hubungan yang signifikan antara tingkat pengetahuan ibu tentang difteri dengan perilaku pencegahan penyakit difteri di RT 01, RT 02 dan RT 04 Dusun Ngrame Kasihan Bantul 2011.
\end{abstract}

Kata Kunci: tingkat pengetahuan, perilaku pencegahan, penyakit difteri

Info Artikel:

Artikel dikirim pada 11 Juni 2013

Artikel diterima pada 11 Juni 2013

\section{PENDAHULUAN}

Indonesia sehat 2010 adalah visi pembangunan kesehatan nasional yang menggambarkan masyarakat Indonesia di masa depan penduduknya hidup dalam lingkungan sehat. Perilaku sehat adalah perilaku proaktif untuk memelihara dan meningkatkan kesehatan, mencegah resiko terjadinya penyakit, melindungi diri dari ancaman penyakit serta berperan aktif dalam gerakan kesehatan masyarakat. Salah satu perilaku sehat yang harus di ciptakan untuk menuju Indonesia sehat yang harus diciptakan untuk menuju Indonesia sehat 2010 adalah perilaku. Pencegahan dan penanggulangan penyakit dengan kegiatan imunisasi dan menerapkan PHBS(1).

Pada kenyataannya, kesadaran masyarakat untuk berperilaku sehat masih belum seperti yang diharapkan, walaupun beberapa kegiatan yang bertujuan untuk meningkatkan kesadaran masyarakat untuk berperilaku yang sehat telah dilaksanakan dalam kegiatan PHBS terdapat beberapa tatanan, tiga tatanan yang menjadi utama sasaran PHBS adalah tatanan rumah tangga, tatanan institusi dan tatanan tempat-tempat umum. PHBS tatanan rumah tangga mempunyai daya ungkit yang paling besar terhadap perubahan perilaku masyarakat secara umum. Berdasarkan laporan kesehatan provinsi DIY untuk persentase rumah tangga berperilaku hidup bersih dan sehat $66,49 \%$, kabupaten Bantul menduduki urutan kedua dari bawah yaitu dengan $57,55 \%$, dan wilayah Puskesmas Kasihan II 86,54\%(2).

Difteri merupakan salah satu penyakit menular yang dapat dicegah dengan imunisasi (PD3I). Penyakit yang dapat dicegah dengan imunisasi (PD3I) seperti TBC, diphteri, pertusis, campak, tetanus, polio, dan hepatitis $B$ merupakan salah satu penyebab kematian anak di negara-negara miskin dan berkembang termasuk Indonesia. Penyakit ini sudah lama dikenal, dan mulai banyak dilaporkan pada tahun 1921. Pada 
tahun 1983, WHO melaporkan 92.000 kasus difteri pernafasan yang terjadi di Asia, Afrika, Amerika Tengah, dan Amerika Selatan. Difteri kutan tidak banyak dilaporkan dan jarang menimbulkan toksisitas. Di Amerika Serikat, selama periode tahun 1959-1970, ditemukan 3916 kasus difteri, dan hanya 0,18\% diantaranya menderita difteri kutan(3).

Berdasarkan Depkes RI, KLB difteri pernah terjadi di Indonesia di beberapa provinsi, antara lain di Jawa Barat dengan 25 kasus yang meninggal 4 orang, Jawa Timur dengan 73 kasus yang meninggal 4 orang, Jawa Tengah dengan 11 kasus tidak ada yang meninggal, Kalimantan Timur dengan kasus 2 orang dan tidak ada yang meninggal, Riau dengan kasus 11 orang yang meninggal 1 orang, Sulawesi Tenggara dengan 2 kasus dan tidak ada yang meninggal dan Sumatera Barat 1 kasus dan tidak ada yang meninggal(4).

Berdasarkan penelitian yang pernah dilakukan oleh Wahab, di DIY pernah terjadi KLB pada tahun 1986-1992 dengan penderita sebanyak 32 orang yang di rawat di RS Sardjito(5). Sebelum itu, di Sleman juga pernah terjadi KLB dengan jumlah penderita sebanyak 94 orang, sedangkan di Bantul ditemukan 2 kasus pada tahun 2003 dan tidak ada angka kematian. Semakin bertambah tahun, semakin terjadi penurunan angka kejadian difteri seiring dengan ditemukannya vaksin difteri dan ditetapkannya program universal child immunization (UCl). Akan tetapi penyakit difteri tidak boleh dianggap sepele karena pencegahan difteri tidak hanya dengan imunisasi saja, namun perilaku hidup bersih dan sehat juga sangat berpengaruh terhadap timbulnya penyakit difteri.

Berdasarkan data dari Puskesmas Kasihan II, ditemukan 1 orang anak di Dusun Ngrame pernah menderita difteri pada tahun 1995, akan tetapi anak tersebut sembuh setelah diberikan pengobatan dan isolasi. Berdasarkan studi pendahuluan di Dusun Ngrame, peneliti melakukan observasi selama 3 hari, dari 10 ibu yang diberi pertanyaan mengenai pengetahuan tentang difteri dan pencegahannya, 4 ibu diantaranya mengatakan belum mengatahui tentang difteri dan pencegahannya. Tiga ibu diantaranya mengatakan telah melakukan imunisasi DPT untuk pencegahan penyakit akan tetapi belum mengetahui bahwa fungsi dari imunisasi DPT salah satunya adalah mencegah penyakit difteri, 3 ibu yang lain memiliki pengetahuan cukup baik tentang difteri akan tetapi untuk pencegahannya masih belum baik, yaitu masih sebatas tentang imunisasi, sedangkan pencegahan dengan PHBS belum cukup dan didukung dengan keadaan lingkungan sekitar rumah yang masih terlihat kotor.
Secara umum tujuan penelitian untuk mengetahui hubungan tingkat pengetahuan ibu tentang difteri dengan perilaku pencegahan penyakit difteri di RT 01, RT 02 dan RT 04 Dusun Ngrame Kasihan Bantul 2011. Secara khusus untuk mengetahui tingkat pengetahuan ibu tentang difteri, mengetahui perilaku ibu tentang pencegahan penyakit difteri, mengetahui keeratan hubungan tingkat pengetahuan ibu tentang difteri dengan perilaku pencegahan penyakit difteri di RT 01, RT 02 dan RT 04 Dusun Ngrame Kasihan Bantul 2011.

\section{BAHAN DAN METODE}

Jenis penelitian ini adalah jenis penelitian analitik dengan rancangan penelitian ini adalah cross sectional. Populasinya adalah semua ibu-ibu yang berada di Dusun Ngrame, Kasihan, Bantul yang berjumlah 275 orang ibu. Subjek penelitian adalah ibu yang berada di RT 01, RT 02 dan RT 04 Dusun Ngrame, Kasihan, Bantul. Sampel yang digunakan dalam penelitian ini adalah ibu-ibu yang memenuhi kriteria inklusi warga RT 01, RT 02 dan RT 04 Dusun Ngrame, bersedia menjadi responden, wanita yang menikah dan memiliki anak. Kriteria eksklusi tidak bersedia menjadi responden. Teknik sampling yang digunakan dalam pengambilan sampel adalah purposive sampling. Penelitian ini dilakukan di RT 01, RT 02 dan RT 04 Dusun Ngrame, Kasihan, Bantul, dilaksanakan selama 7 hari yaitu pada tanggal $14-20$ Maret 2012.

Variabel bebas yang digunakan dalam penelitian ini adalah tingkat pengetahuan ibu tentang difteri. Variabel pengganggu dalam penelitian ini adalah umur ibu, pendidikan ibu, pekarjaan ibu, pendapatan.

Dalam penelitian ini untuk mengetahui validitas instrumen dengan menggunakan rumus pearson product moment. Uji validitas dan reliabilitas dilaksanakan di Dusun Gatak Kasihan dengan jumlah responden sebanyak 30 orang. Untuk menguji validitas dan reliabilitas dilakukan uji coba instrumen pada responden.

\section{HASIL DAN BAHASAN}

Jumlah penduduk di Dusun Ngrame RT 01 , RT 02 dan RT 04 yaitu berjumlah 735 jiwa dengan populasi ibu sebanyak 275 orang ibu. Sampel dalam penelitian ini berjumlah 69 orang ibu.

Berdasarkan Tabel 1 mayoritas tingkat pengetahuan ibu tentang difteri adalah baik sebanyak 59 orang $(85,5 \%)$ dan minoritas memiliki tingkat pengetahuan kurang sebanyak 1 orang $(1,4 \%)$. 
Tabel 1. Distribusi Frekuensi Tingkat Pengetahuan lbu tentang Difteri di RT 01, RT 02 dan RT 04 Dusun Ngrame Kasihan Bantul 2011

\begin{tabular}{lcc}
\hline Tingkat Pengetahuan & f & $\%$ \\
\hline Baik & 59 & 85,5 \\
Cukup & 9 & 13 \\
Kurang & 1 & 1,4 \\
Buruk & 0 & 0 \\
Jumlah & 69 & 100 \\
\hline
\end{tabular}

Sumber: Data Primer Tahun 2012

Tabel 2. Distribusi Frekuensi Perilaku Pencegahan Penyakit Difteri di RT 01, RT 02 dan RT 04 Dusun Ngrame Kasihan Bantul 2011

\begin{tabular}{lcc}
\hline Perilaku & f & $\%$ \\
\hline Baik & 58 & 84,1 \\
Sedang & 10 & 14,5 \\
Buruk & 1 & 1,4 \\
Jumlah & 69 & 100 \\
\hline
\end{tabular}

Sumber: Data Primer Tahun 2012

Berdasarkan Tabel 2 menunjukkan bahwa mayoritas ibu memiliki perilaku yang baik yaitu sebanyak 58 orang $(84,1 \%)$ dan minoritas berperilaku buruk yaitu sebanyak 1 orang $(1,4 \%)$.

Berdasarkan Tabel 3 menunjukkan bahwa ibu dengan tingkat pengetahuan baik dan memiliki perilaku yang baik sebanyak 56 orang $(94,9 \%)$ dan memiliki perilaku sedang sebanyak 3 orang $(5,1 \%)$. Kemudian ibu dengan pengetahuan cukup yang memiliki perilaku sedang sebanyak 7 orang $(77,8 \%)$ dan memiliki perilaku baik sebanyak 2 orang $(22,2 \%)$. Selanjutnya ibu dengan pengetahuan kurang memiliki perilaku buruk yaitu 1 orang $(100 \%)$.

Hasil perhitungan statistik menggunakan uji kendall tau diperoleh $p$-value sebesar 0,000<0,005 $(p<\alpha)$ sehingga disimpulkan bahwa ada hubungan yang signifikan antara tingkat pengetahuan ibu tentang difteri dengan perilaku pencegahan penyakit difteri. Nilai koefisien korelasi positif menunjukkan semakin baik tingkat pengetahuan maka semakin baik perilaku pencegahannya. Keeratan hubungan yang terjadi antara tingkat pengetahuan ibu tentang difteri dengan perilaku pencegahan penyakit difteri termasuk dalam kategori kuat yang ditunjukkan dengan nilai koefisien korelasi sebesar 0,729.

\section{Tingkat Pengetahuan Ibu tentang Difteri di RT 01, RT 02 dan RT 04 Dusun Ngrame Kasihan Bantul 2011}

Tingkat pengetahuan ibu tentang difteri di RT 01, RT 02 dan RT 04 Dusun Ngrame Kasihan Bantul mayoritas baik yaitu sebanyak 59 orang $(85,5 \%)$. Hal ini menunjukkan responden sudah mendapatkan informasi mengenai penyakit difteri dengan baik. Informasi yang didapatkan responden umumnya berasal dari televisi, internet, majalah, atau koran. Meskipun daerah penelitian berada di pinggiran kota, akan tetapi masyarakat setempat banyak yang sudah berkembang mengikuti perkembangan teknologi. Selain itu juga perkumpulan ibu-ibu juga berperan dalam menambah pengetahuan para ibu. Banyaknya informasi yang diperoleh akan meningkatkan pengetahuan ibu tentang difteri. Hal ini sesuai dengan pendapat Notoatmodjo, pengetahuan umumnya datang dari pengalaman dan dapat diperoleh dari informasi dari berbagai media seperti televisi, majalah, teman, buku, dan surat kabar(6). Pengetahuan merupakan suatu bentuk dari manusia yang diperolehnya melalui pengalaman, perasaan, akal pikiran, dan intuisinya setelah orang melakukan penginderaan terhadap suatu objek tertentu.

\section{Perilaku Pencegahan Penyakit Difteri di RT 01, RT 02 dan RT 04 Dusun Ngrame Kasihan Bantul 2011}

Berdasarkan Tabel 2 menunjukkan bahwa perilaku pencegahan penyakit difteri mayoritas berperilaku baik yaitu 58 orang $(84,1 \%)$. Mayoritas responden berperilaku baik, yang akan berpengaruh terhadap perilakunya dalam pencegahan penyakit difteri. Selain umur, pendidikan, pekerjaan dan pendapatan ibu, perilaku baik ini juga dapat dipengaruhi oleh tradisi masyarakat setempat

Tabel 3. Tabulasi Silang antara Tingkat Pengetahuan tentang Difteri dengan Perilaku Pencegahan Penyakit Difteri pada Ibu RT 01, RT 02 dan RT 04 Dusun Ngrame Kasihan Bantul 2011

\begin{tabular}{|c|c|c|c|c|c|c|c|c|c|c|}
\hline \multirow{3}{*}{$\begin{array}{c}\text { Tingkat } \\
\text { Pengetahuan }\end{array}$} & \multicolumn{6}{|c|}{ Perilaku } & \multirow{2}{*}{\multicolumn{2}{|c|}{ Total }} & \multirow{3}{*}{ p-value } & \multirow{3}{*}{$\mathbf{T}$} \\
\hline & \multicolumn{2}{|c|}{ Baik } & \multicolumn{2}{|c|}{ Sedang } & \multicolumn{2}{|c|}{ Buruk } & & & & \\
\hline & $f$ & $\%$ & $f$ & $\%$ & $f$ & $\%$ & $f$ & $\%$ & & \\
\hline Baik & 56 & 94,9 & 3 & 5,1 & 0 & 0 & 59 & 100 & 0,000 & 0,729 \\
\hline Cukup & 2 & 22,2 & 7 & 77,8 & 0 & 0 & 9 & 100 & & \\
\hline Kurang & 0 & 0 & 0 & 0 & 1 & 100 & 1 & 100 & & \\
\hline Jumlah & 58 & 84,1 & 10 & 14,5 & 1 & 1,4 & 69 & 100 & & \\
\hline
\end{tabular}

Sumber: Data Primer Tahun 2012 
yang selalu berbaur dan bersosialisasi dengan sesama warga masyarakat dalam bentuk kegiatan sosial, sehingga dalam pergaulan masyarakat akan membawa pengaruh terhadap individu tersebut. Kegiatan-kegiatan sosial seperti pengajian, arisan, PKK yang dilakukan oleh ibu-ibu tersebut membawa pengaruh positif. Selain untuk bersilaturahmi, para ibu-ibu juga saling berbagi pengetahuan, informasi dan pengalaman dalam berbagai hal, termasuk tentang penyakit difteri. Hal ini sesuai dengan penelitian Handayani bahwa pengetahuan tentang sesuatu hal menyebabkan orang akan besikap positif terhadap hal tersebut, selanjutnya sikap yang positif akan mempengaruhi niat untuk ikut dalam suatu kegiatan. Sehingga semakin baik tingkat pengetahuan ibu tentang difteri maka semakin baik pula perilaku pencegahan penyakit difteri(7).

\section{Tingkat Pengetahuan Ibu tentang Difteri dengan Perilaku Pencegahan Penyakit Difteri di RT 01, RT 02 dan RT 04 Dusun Ngrame Kasihan Bantul}

Interpretasi hasil pada uji statistik dengan analisis kendall tau menunjukkan nilai $p=0,000$ ( $p<0,05$ ) yang menunjukkan ada hubungan tingkat pengetahuan ibu tentang difteri dengan perilaku pencegahan penyakit difteri dengan tingkat keeratan hubungan dalam kategori kuat $(0,729)$.

Keeratan hubungan dalam kategori kuat dapat disebabkan oleh beberapa faktor antara lain dilakukannya pengendalian pada variabelvariabel pengganggu pada penelitian ini. Akan tetapi pengendalian ini bukan satu-satunya faktor yang mempengaruhi kuatnya keeratan hubungan antara kedua variabel yang diteliti. Karena kemungkinan besar hasil akan lebih baik jika dilakukan pengendalian yang lebih terperinci, misalnya untuk variabel umur dibuat rentang umur dalam bentuk interval, tidak dicari umur tertentu yang benar-benar sama, misalnya ibu yang berumur 30 tahun saja. Kemudian pada variabel pekerjaan, variabel ini hanya dibagi dua kategori yaitu PNS dan swasta. Kemungkinan keeratan akan lebih kuat jika kategori swasta dirincikan menjadi subkategori yang lebih spesifik, misalnya buruh, petani, pedagang dan lain sebagainya. Selain itu menurut beberapa pengarang, masih ada variabel pengganggu lain yang tidak termasuk dalam penelitian ini. Hal-hal tersebut dapat mempengaruhi keeratan hubungan dari kedua variabel yang diteliti, dan jika dikembangkan lagi maka keeratan hubungan akan semakin kuat. Menurut Ismail bahwa pengetahuan memang berkorelasi dengan sikap, disamping itu dengan tindakan dan perilaku, namun hal ini tidak bersifat mutlak. Terbukti bahwa hubungan variabel-variabel tersebut tidaklah konsisten(8).

Berdasarkan Tabel 3 ibu dengan tingkat pengetahuan baik memiliki perilaku sedang sebanyak 3 orang $(5,1 \%)$. Kemudian ibu dengan pengetahuan cukup memiliki perilaku baik sebanyak 2 orang $(22,2 \%)$. Pada hasil tersebut menunjukkan bahwa tidak semua orang yang memiliki tingkat pengetahuan baik selalu berperilaku baik dan tidak semua orang yang tingkat pengetahuannya sedang selalu berperilaku yang kurang baik. Menurut Saman bahwa perilaku yang baik tidak otomatis dilakukan oleh orang yang berpengetahuan baik(9). Hal ini tergantung sikap dan kemauan individu yang bersangkutan.

Sebelum seseorang mengadopsi perilaku, di dalam diri seseorang tersebut terjadi proses yang berurutan, yaitu: kesadaran (awarness) yang artinya dimana orang tersebut menyadari dalam arti mengetahui terlebih dahulu terhadap stimulus, dalam hal ini ibu yang mengetahui dan menyadari berbagai hal tentang pentingnya perilaku pencegahan penyakit difteri. Setelah itu ibu mengetahui dan menyadari hal tersebut maka timbul ketertarikan (interest), yaitu ibu tertarik untuk melakukan perilaku pencegahan penyakit difteri sesuai dengan informasi yang diketahui sebelumnya. Selanjutnya dengan melakukan evaluasi (evaluation) atau menimbangnimbang baik dan tidaknya stimulus tersebut bagi dirinya atau dalam hal ini adalah subjek mulai menunjukkan perilaku terhadap objek, artinya ibu mulai berfikir untuk menjaga kesehatan dengan menimbang baik dan buruknya dengan perilaku pencegahan penyakit difteri. setelah itu proses mencoba perilaku (trial) yang artinya ibu mencoba untuk melakukan tindakan perilaku pencegahan penyakit difteri yang didasarkan atas berbagai pertimbangan yang telah difikirkan sebelumnya hingga beradaptasi dengan perilaku (adaptation), yaitu ibu mulai terbiasa untuk melakukan perilaku pencegahan penyakit difteri(6). Akan tetapi, hasil penelitian ini bertentangan dengan penelitian Siti yang menyimpulkan tidak ada hubungan antara pengetahuan ibu rumah tangga dengan terapan perilaku hidup bersih dan sehat pada tatanan rumah tangga Desa Dempet Kabupaten Demak dengan $p$-value 0,777 , menurut Siti hal ini dikarenakan kurang kesadaran masyarakat Desa Dempet yang kebanyakan memiliki pengetahuan yang baik tapi tidak menerapkannya pada perilaku di kehidupan sehari-hari(10).

Penelitian ini sesuai dengan penelitian yang dilakukan oleh Ramdaniati dengan judul hubungan 
antara pengetahuan, sikap dan sosiodemografi dengan perilaku hidup bersih dan sehat pada ibu rumah tangga RW 04 Manggarai Jakarta Selatan 2008 yang mengatakan bahwa ada hubungan yang positif antara pengetahuan dengan perilaku hidup bersih dan sehat di RW 04 Manggarai Jakarta Selatan 2008 dengan $p$-value sebesar 0,002(11).

\section{SIMPULAN DAN SARAN}

Berdasarkan hasil penelitian dapat disimpulkan tingkat pengetahuan ibu tentang difteri mayoritas baik yaitu sebanyak 59 orang $(85,5 \%)$, perilaku pencegahan penyakit difteri mayoritas baik yaitu 58 orang $(84,1 \%)$, terdapat hubungan yang signifikan antara tingkat pengetahuan ibu tentang difteri dengan perilaku pencegahan penyakit difteri di RT 01, RT 02 dan RT 04 Dusun Ngrame Kasihan Bantul, memiliki keeratan hubungan dalam kategori kuat dengan koefisien sebesar 0,729.

Saran bagi responden hendaknya dapat mempergunakan pengetahuan yang sudah baik mengenai penyakit difteri untuk mempertahankan perilaku pencegahan yang baik terhadap penyakit difteri. Agar dilakukan penelitian terhadap kemungkinan faktor lain yang mempengaruhi perilaku pencegahan penyakit difteri seperti faktor umur, pendidikan, pekerjaan dan pendapatan. Menambah wawasan dan referensi dalam hal melakukan penelitian khususnya tentang hubungan tingkat pengetahuan ibu tentang difteri dengan perilaku pencegahan penyakit difteri. Bagi Petugas Puskesmas Kasihan II perlu promosi kesehatan mengenai difteri karena menurut penuturan ibu-ibu yang menjadi responden di Dusun Ngrame belum pernah dilakukan penyuluhan tentang penyakit difteri. Sehingga diharapkan bisa memiliki tingkat pengetahuan yang lebih baik lagi tentang difteri.

\section{RUJUKAN}

1. Departemen Kesehatan RI. Profil Kesehatan Indonesia 1999. Jakarta: Departemen Kesehatan R.I; 2000.

2. Dinas Kesehatan DIY. Profil Kesehatan Provinsi DIY 2004. Yogyakarta: Dinas Kesehatan DIY; 2005.

3. Dinas Kesehatan DIY. Profil Kesehatan Provinsi DIY 2005. Yogyakarta: Dinas Kesehatan DIY; 2006

4. Departemen Kesehatan RI. Profil Pengendalian Penyakit \& Penyehatan Lingkungan. Jakarta: Departemen Kesehatan R.I; 2008.

5. Wahab S. Blokade Cabang Berkas Kiri pada Miokarditis Difteri. Berkala IImu Kedokteran. 1993;25(2).

6. Notoatmodjo S. Promosi Kesehatan dan IImu Perilaku. Jakarta: PT Rineka Cipta; 2007.

7. Handayani. Pengaruh Tingkat Pendidikan Formal Wanita Usia Subur Terhadap Pengetahuan Tentang Pemeriksaan Payudara Sendiri (SADARI) Sebagai Upaya Deteksi Dini Kanker Payudara. Yogyakarta: FK UGM; 2001.

8. Ismail. Psikologi Umum Buku Panduan Mahasiswa. Jakarta: PT Prenelalindo; 1991.

9. Saman. Sosiologi IImu Kesehatan Masyarakat Prinsip-prinsip Dasar. Bandung: Alfabeta; 2005.

10. Siti. Hubungan Antara Pengetahuan Ibu Rumah Tangga Dengan Terapan Perilaku Hidup Bersih Dan Sehat Pada Tatanan Rumah Tangga Desa Dempet Kabupaten Demak. Semarang: Fakultas IImu Keolahragaan UNNES; 2007.

11. Ramdaniati S. Hubungan Antara Pengetahuan, Sikap dan Sosiodemografi dengan Perilaku Hidup Bersih dan Sehat pada Ibu Rumah Tangga RW 04 Manggarai Jakarta Selatan 2008. Jakarta: FKM UI; 2008. 